\title{
ARTIGOS
}

Submetido em 28.08.2016. Aprovado em 22.06.2017

Avaliado pelo processo de double blind Review. Editora Científica: Jane Mendes Ferreira

DOI: http://dx.doi.org/10.1590/So034-759020170607

\section{ESTÁGIOS DO CICLO DE VIDA E PERFIL DE EMPRESAS FAMILIARES BRASILEIRAS}

\author{
Life cycle stages and Brazilian family business profiles \\ Etapas del ciclo de vida y perfil de las empresas familiares brasileñas
}

\begin{abstract}
RESUMO
As características distintivas das empresas familiares, como a influência exercida pela família, adicionam complexidade aos modelos de ciclo de vida organizacional. Esta pesquisa analisa a relação entre os estágios do ciclo de vida organizacional (Lester, Parnell, Carraher, \& Pamell, 2003) e os elementos de influência da família na empresa no modelo F-PEC (Poder, Experiência e Cultura). 0 estudo foi desenvolvido por meio de amostra de 117 empresas familiares brasileiras, sem a participação de empresas com ações negociadas em bolsa, e tratamento estatístico por meio de modelo de equações estruturais. Como achados, pode-se dizer que os elementos do F-PEC foram parcialmente identificados na amostra. 0 poder indica o controle da empresa pela família; a experiência indica o papel das diferentes gerações; e a cultura, os valores dos controladores. Em particular, deve ser destacado que, no nascimento, o poder e a cultura têm papéis importantes; na maturidade, a experiência e a cultura se destacam; e, no rejuvenescimento, o poder e a cultura foram identificados como caracterizadores. Em termos de artigo exploratório, contribui para o entendimento das organizações, proporcionando indicações para o desenvolvimento de análises comparativas e a atuação sobre as variáveis que proporcionam o planejamento de migração para estágios mais desejáveis, como crescimento, maturidade e rejuvenescimento.
\end{abstract}

PALAVRAS-CHAVE | Empresas familiares, ciclo de vida organizacional, gerações, modelo F-PEC, empresas brasileiras.

\section{FÁBIO FREZATTI \\ frezatti@usp.br \\ Professor da Universidade de São \\ Paulo, Faculdade de Economia \\ Administração e Contabilidade - \\ São Paulo - SP, Brasil}

\section{DIÓGENES DE SOUZA BIDO}

diogenesbido@yahoo.com.br

Professor da Universidade

Presbiteriana Mackenzie, Centro

de Ciências Sociais e Aplicadas -

São Paulo - SP, Brasil

\section{DANIEL MAGALHÃES MUCCI}

danielmmucci@usp.br Doutorando em Controladoria e Contabilidade pela Universidade de São Paulo, Faculdade de Economia Administração e Contabilidade - São Paulo - SP, Brasil

\section{FRANCIELE BECK \\ fbeck@furb.br \\ Professora da Fundação \\ Universidade Regional de \\ Blumenau-Blumenau - SC, Brasil}

\section{ABSTRACT}

The distinctive features of family firms, such as family influence, add complexity to organizational life-cycle models in terms of the different stages of development. This research analyzes the relationship between stages of the organizational life cycle proposed by Lester et al. (2003) and the elements of influence of the F-PEC family (power, experience, and culture). The study was developed through a sample of 117 Brazilian family companies, without the participation of companies with shares traded on the stock exchange, and employed statistical treatment of the data through a structural equation model. As a result, the elements of F-PEC were partially identified in the sample. Power indicates the control of the company by the family, experience indicates the role of the different generations, and culture indicates the values of the controllers. In particular, it should be pointed out that, at birth, power and culture play important roles; in maturity, experience and culture stand out, and in rejuvenation, power and culture have been identified as characteristic. As an exploratory analysis, the article contributes to the understanding of organizations, by indicating the development of comparative analyses and performance on the variables that provide migration planning to more desirable stages, such as growth, maturity, and rejuvenation.

KEYWORDS I Family companies, organizational life cycle, generations, F-PEC model, Brazilian companies.

\section{RESUMEN}

Las características distintivas de las empresas familiares, como la influencia ejercida por la familia, agregan complejidad a los modelos de ciclo de vida organizacional. Esta investigación analiza la relación entre las etapas del ciclo de vida organizacional propuestas por Lester et al. (2003) y los elementos de influencia de la familia en la empresa del modelo F-PEC (Poder, Experiencia y Cultura). Este estudio se desarrolló a través de una muestra de 117 empresas familiares brasileñas -sin participación de empresas con acciones negociadas en bolsa-, y tratamiento estadístico por medio de modelo de ecuaciones estructurales. En lo que se refiere a resultados, se puede observar que los elementos del F-PEC fueron parcialmente identificados en la muestra. El poder indica el control de la empresa por la familia; la experiencia, el papel de las diferentes generaciones; y la cultura indica los valores de los controladores. En particular, debe destacarse que, en el nacimiento, el poder y la cultura tienen papeles importantes; en la madurez, la experiencia y la cultura se destacan y, en el rejuvenecimiento, el poder y la cultura se identifican como caracterizadores. El presente trabajo, como estudio exploratorio, contribuye al entendimiento de las organizaciones al proporcionar recomendaciones para el desarrollo de análisis comparativos y la actuación sobre las variables que propicien la planificación de migración a etapas más deseables, como crecimiento, madurez y rejuvenecimiento.

PALABRAS CLAVE I Empresas familiares, ciclo de vida organizacional, generaciones, modelo F-PEC, empresas brasileñas. 


\section{INTRODUÇÃO}

A evolução das empresas é algo que, de alguma maneira, vem tomando a atenção da comunidade. Pesquisadores têm procurado entender a organização na sua trajetória de vida, num primeiro momento epistemologicamente desvinculada de uma abordagem econômica, mas com elementos que permitam entender o seu estágio de vida e suas possibilidades de mudanças. Com os estudos sobre ciclo de vida das organizações, pretende-se entender as suas mudanças a partir de elementos que se assemelham com os ciclos vivenciados pelas pessoas, quais sejam nascimento, crescimento, maturidade, declínio e rejuvenescimento (Lester et al., 2003).

Embora não sejam estudos que pretendem propor elementos preditivos, busca-se entender a evolução das organizações, assim como orientá-las a partir de suas características e identificar causas de ocorrências que, de outra maneira, não seriam percebidas e associadas a alguma variável. Ao compreender as particularidades das empresas nos seus estágios de ciclo de vida, é possível atuar nas mudanças que podem proporcionar seu crescimento e desenvolvimento (Hanks, 1990).

Por sua vez, ainda que a importância das empresas familiares seja um fenômeno mundial, elas são muito diferentes entre si, sendo isso reconhecido pelos estudiosos (Astrachan, Klein, \& Smyrnios, 2002; Dawson \& Mussolino, 2014; Sharma, 2004). Esse é um desafio que afeta o desenvolvimento e a consolidação de conhecimentos sobre o tema.

O tema é ainda mais relevante pelo fato de haver uma sobreposição entre o ciclo de vida da empresa e o ciclo de vida da própria família, o que é espelhado pelo processo de sucessão que ocorre nessas empresas (Barnett, Long, \& Marler, 2012) e pelo horizonte de longo prazo (Berrone, Cruz, \& Gómez-Mejía, 2012). Isso traz implicações sobre o comportamento dessas empresas no que tange ao alcance de objetivos centrados na família, como harmonia, poder, status, entre outros elencados na literatura (Gómez-Mejía, Cruz, Berrone, \& Castro, 2011; GómezMejía, Haynes, Núñez-Nickel, Jacobson, \& Moyano-Fuentes, 2007; Miller \& Breton-Miller, 2014). As prioridades socioemocionais refletidas na cultura da empresa familiar (Berrone et al., 2012; Gómez-Mejía et al., 2011) não são estáticas ao longo do ciclo de vida organizacional (Breton-Miller \& Miller, 2013), inclusive no que se refere à geração que atua na gestão do negócio, que usualmente tem objetivos e expectativas diferentes das outras (Breton-Miller \& Miller, 2013; Schulze \& Kellermanns, 2015).

O tema empresas familiares tem sido tratado no Brasil quanto à ótica da sucessão (Flores \& Grisci, 2012; Oliveira \&
Silva, 2012; Rodrigues, 1991; Silva \& Muniz, 2006; Waiandt \& Davel, 2008), da estrutura de capital (Oro, Beuren, \& Hein, 2009a), da eficiência dos negócios (Oro, Beuren, \& Hein, 2009b), de estudos gerais sobre empresas familiares (Paiva, Oliveira, \& Melo, 2008), da cultura, poder e decisão (Macêdo, 2002), da relação família-empresa (Lescura, Brito, Cappelle, \& Borges, 2012), do processo de planejamento (Terence, 2002), das implicações com a governança (Silva, Silva, \& Silva, 2013) e da profissionalização (Muzzio, 2012).

A leitura do ciclo de vida organizacional e da família tem sido realizada no ambiente brasileiro a partir de pesquisas qualitativas (estudos de caso ou entrevistas) que investigaram a evolução histórica da empresa e de seu modelo de gestão (Cançado, Lima, Muylder, \& Castanheira, 2013; Meireles, Debastiani, \& Rojo, 2015; Oliveira, Alburquerque, \& Pereira, 2012; Três, Serra, Pinto, \& Pereira, 2014; Waiandt \& Davel, 2008), o reconhecimento do legado do fundador (Oliveira et al., 2012) e o período de transição da gestão para as próximas gerações (Bertucci, Campos, Pimentel, \& Pereira, 2009; Cançado et al., 2013; Oliveira et al., 2012; Pereira, Vieira, Garcia, \& Roscoe, 2013). Além disso, há uma vertente de pesquisas empíricas que aplicaram modelos de ciclo de vida e buscaram classificar as empresas da amostra em relação aos diferentes estágios do ciclo de vida organizacional (Grzybovski \& Vieira, 2012; Morais \& Silva, 2014). Esses trabalhos, apesar de adotarem diversos modelos, tendo como frequente o de Greiner (1997), têm interseção, pois discutem a estrutura organizacional, o poder decisório, os sistemas de controle gerencial, bem como outros aspectos. Nesse sentido, seus achados subsidiam a discussão de que existe relação entre a influência da família no negócio e o ciclo de vida organizacional.

A base do modelo de empresa familiar utilizado em alguns desses trabalhos foi o modelo tridimensional proposto por Gersick, Davis, Hampton e Lansberg (1997), que propõe a discussão da evolução das dimensões de propriedade, família e gestão ao longo do tempo. Esse modelo discute uma tipologia de desenvolvimento da empresa familiar, mas possui limitações observadas no campo empírico (Andrade, Grzybovski, \& Lima, 2004; Cançado et al., 2013), talvez por não capturar elementos distintivos da empresa familiar, como experiência e cultura, que são evidenciados por outros modelos de empresa familiar (Astrachan et al., 2002; Dawson \& Mussolino, 2014). 0 modelo adotado nesta pesquisa, o F-PEC (Astrachan et al., 2002), baseia-se em vários elementos do modelo Gersick et al. (1997) e os aperfeiçoa.

Nesse sentido, o olhar para o ciclo de vida, de um lado, proporciona uma oportunidade de separação de elementos relevantes que contemplam o desenvolvimento das organizações e as características da influência da família na empresa familiar; 
do outro lado, enriquece ainda mais a perspectiva do ciclo de vida organizacional (Breton-Miller \& Miller, 2013; Cançado et al., 2013).

Lester et al. (2003) está entre os modelos existentes na literatura que tratam o ciclo de vida organizacional em empresas de pequeno e médio portes. O modelo de Lester et al. (2003) traz características de tomada de decisões, processamento de informações, estrutura e procedimentos operacionais (Lester \& Parnell, 2008), ao considerar atividades que se alteram durante a trajetória de vida (Ven, 1992).

Há uma lacuna na literatura de pesquisas no que se refere à união dessas duas abordagens, ou seja, que discutem de maneira integrada tanto as características do ciclo de vida quanto as características distintivas da empresa familiar. Buscando preencher essa lacuna, utilizamos construtos apoiados em Astrachan et al. (2002) para as características do F-PEC e em Miller e Friesen (1983, 1986) e Lester et al. (2003) para os estágios do ciclo de vida.

No presente trabalho, procuramos unir o entendimento do ciclo de vida organizacional e as características da empresa familiar seguindo a abordagem denominada essence (Dawson \& Mussolino, 2014), ao discutir de que forma as dimensões de poder, experiência e cultura (F-PEC) se relacionam com o ciclo de vida organizacional.

Como consequência, a questão de pesquisa que direciona o presente artigo é: Qual a relação entre os estágios do ciclo de vida e as características distintivas das empresas familiares (poder, experiência e cultura)? Da questão de pesquisa, decorre o seguinte objetivo: identificar de que forma os estágios do ciclo de vida se relacionam com as características das empresas familiares (poder, experiência e cultura).

Esse conhecimento é relevante para que se entenda como a influência da família na empresa está associada ao estágio de desenvolvimento organizacional. Além disso, permite caracterizar o perfil de interação dos executivos das famílias no controle e na gestão do negócio em relação a cada estágio do ciclo de vida.

Esse artigo contribui para a discussão da associação de duas abordagens, o modelo F-PEC, que é uma abordagem presente na área de empresas familiares, e os estágios do ciclo de vida organizacional. Como discutimos anteriormente, as pesquisas brasileiras privilegiaram a aplicação do modelo de ciclo de vida em estudos de caso, buscando indicar a evolução de uma empresa, ou em carácter exploratório, ao classificar as empresas em determinado estágio. Além disso, os trabalhos que focalizaram os elementos da empresa familiar utilizaram o modelo de Gersick et al. (1997), que omite elementos como cultura e experiência, características distintivas da empresa familiar; demonstramos, neste artigo, que eles diferem entre os estágios do ciclo de vida organizacional. Além disso, a literatura internacional propõe discussões do ponto de vista teórico, como nos trabalhos de Gersick et al. (1997) e Miller e Breton-Miller (2014), ou seja, novos estudos empíricos podem promover avanços no campo.

É possível identificar na literatura estudos que discutiram a configuração de práticas de gestão de modo amplo (Bedford \& Malmi, 2015) ou especificamente em relação a uma prática como o orçamento (Sponem \& Lambert, 2016), ou que discutiram configurações de empresas familiares (Dekker, Lybaert, Steijvers, Depaire, \& Mercken, 2012; Gersick et al., 1997; Westhead \& Howorth, 2007). Por fim, ao analisar a abordagem do ciclo de vida no contexto de empresa familiar e trazer elementos de influência da família na gestão (modelo F-PEC), também estamos contribuindo para a literatura que discute configurações de empresas familiares (Dekker et al., 2012; Gersick et al., 1997; Westhead \& Howorth, 2007).

\section{REVISÃO DA LITERATURA}

A literatura aponta as empresas familiares como uma forma de organização predominante no Brasil e no mundo, dedicadas à produção de bens e serviços no cenário empresarial, destacando, desse modo, sua importância quanto aos aspectos econômicos, políticos, sociais e culturais (Paiva et al., 2008; Petry \& Nascimento, 2009; Price Waterhouse-Coopers [PWC], 2010). Em termos numéricos, estima-se que as empresas familiares sejam responsáveis por $48 \%$ do Produto Interno Bruto (PIB) brasileiro e que alcancem em torno de $60 \%$ da geração de empregos (Petry \& Nascimento, 2009). A relevância das empresas familiares também é tratada no ambiente internacional (Debicki, Matherne, Kellermanns, \& Chrisman, 2009; Gersick et al., 1997; Lethbridge, 1997).

O construto teórico da pesquisa leva em conta duas vertentes. Primeiro, discutir os conceitos sobre empresas familiares e os aspectos que a literatura aponta como cruciais para sua caracterização; segundo, tratar sobre o ciclo de vida organizacional.

\section{Conceito e modelo de empresas familiares}

Para efeitos de desenvolvimento desta pesquisa, foi seguida a abordagem de Zellweger, Nason e Nordqvist (2011), que se utilizam da definição de Chua, Chrisman e Sharma (1999, p. 25), ajustando-a de modo a se tornar contemporânea:

A empresa familiar é uma empresa governada e/ou gerenciada com a intenção de moldar e 
perseguir a visão de manutenção de negócios por uma coalizão dominante controlada pelos membros de uma mesma família ou pequeno número de famílias de forma que seja sustentável através de gerações de família ou famílias.

Embora a definição de empresa familiar pareça bastante simples de ser estabelecida e operacionalizada (Chrisman, Chua, \& Sharma, 2005), existem várias alternativas de combinação de elementos, o que gera dificuldades de se pesquisar o tema.

O fato de a família ser proprietária e/ou gestora de uma organização pode ocorrer em vários níveis, tanto no que se refere à pulverização de donos como por parte de os executivos não serem membros da família. Assim, a visão da manutenção dos negócios pode ser distinta ou de diferente complexidade, dependendo do perfil familiar durante o seu desenvolvimento.

Deve ser destacada a perspectiva de que não basta o controle ser feito por uma família, mas, sim, que exista a intenção de que o negócio seja mantido por ela. Alguns autores distinguem empresas de um "fundador solitário", como a Microsoft, e empresas em que a família como um todo participa no negócio (Miller, Breton-Miller, Lester, \& Canella, 2007). Esse é um fator fundamental, difícil de ser constatado em empresas mais jovens, da primeira geração, por exemplo, ou mesmo de outras gerações em situação em que a família questiona a continuidade da empresa em seu poder. Como consequência, uma startup acaba ficando fora do contexto deste estudo por "não ter passado" e, em muitos casos, não ter por trás a perspectiva da perenidade do controle de uma ou várias famílias. Isso é dito para que se perceba a dificuldade de tratamento da empresa familiar na literatura.

No contexto internacional, os estudos sobre empresas familiares têm se apoiado em diversas vertentes teóricas (Chrisman et al., 2005; Dawson \& Mussolino, 2014): teoria da agência (Miller \& Breton-Miller, 2014; Schulze, Lubatkin, \& Dino, 2003), F-PEC (Astrachan et al., 2002), teoria do steward (Breton-Miller, Miller, \& Lester, 2011; Miller \& Breton-Miller, 2006), resource-based view (Chrisman et al., 2005; Sirmon \& Hitt, 2003) e teoria da riqueza socioemocional (Berrone et al., 2012; GómezMejía et al., 2011). Trata-se de diferentes abordagens conceituais que, fundamentalmente, são ancoradas em perspectiva de maior ou menor objetividade na caracterização da empresa familiar.

Nesse sentido, o modelo F-PEC (Astrachan et al., 2002) foi escolhido e utilizado como base para a captação das características das empresas a partir de três dimensões, que são o poder, a experiência e a cultura (Figura 1). Os principais motivos de sua escolha foram: (i) referencial alinhado com o foco da pesquisa, permitindo a utilização do construto para a pesquisa, e, (ii) dado o estado da arte, a relativa objetividade das informações solicitadas, o que pode proporcionar o benefício da credibilidade do que se pretende captar e o que o respondente proporciona. Cabe destacar, segundo Dawson e Mussolino (2014), que o F-PEC agrega elementos que caracterizam a empresa familiar e que são considerados na definição de Chua et al. (1999). Desse modo, o classificam dentro da abordagem do "essence" de empresa familiar.

\section{Figura 1. Modelo F-PEC}

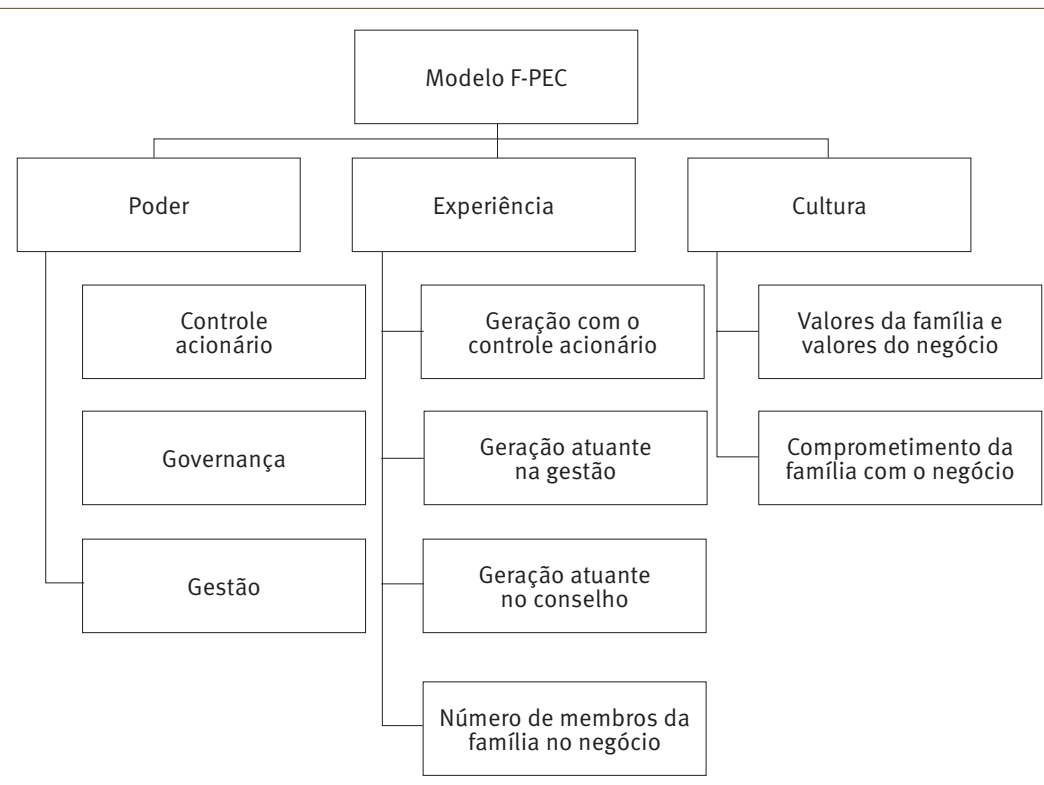

Fonte: Adaptado de Astrachan et al. (2002, p. 52). 
0 poder é tratado (Astrachan et al., 2002) separando-se a propriedade, a governança e a participação na gestão. No que se refere à propriedade, caracteriza-se pela participação da família no controle acionário e pela existência de acionista externo. A existência de conselho que tenha atividades de governança pressupõe a mesma perspectiva, ou seja, a participação dos membros da família e externos. Duller, Feldbauer-Durstmüller e Mitter (2011) não encontraram evidências de impacto de diferentes gerações sobre a qualidade da governança estabelecida nas organizações. No que se refere à participação na gestão, os resultados indicam uma atuação dos membros da família fundamentalmente diretiva.

Em termos de experiência, o modelo destaca qual(is) geração(ões) participa(m) na propriedade, em termos de participação acionária, e também na governança e na gestão (Astrachan et al., 2002). Essas diferentes combinações proporcionam distinções em termos de perfis de organizações.

Finalmente, em termos de modelo, a cultura indica os elementos de valores e premissas da família que são aderentes aos negócios, assim como os compromissos e a dedicação dos membros da família com a organização (Astrachan et al., 2002). Os próprios desenvolvedores do modelo F-PEC introduziram análise simplificadora quanto às variáveis a tratar (Klein, Astrachan, \& Smyrnios, 2005). Nesta pesquisa, foi usada a escala de Klein et al. (2005), para mensurar poder e experiência, e os três melhores itens, do ponto de vista de validade de conteúdo, para mensurar a cultura, sendo apresentados no Quadro 1.

\section{Quadro 1. Escalas para mensuração dos construtos - Indicadores utilizados na pesquisa - F-PEC}

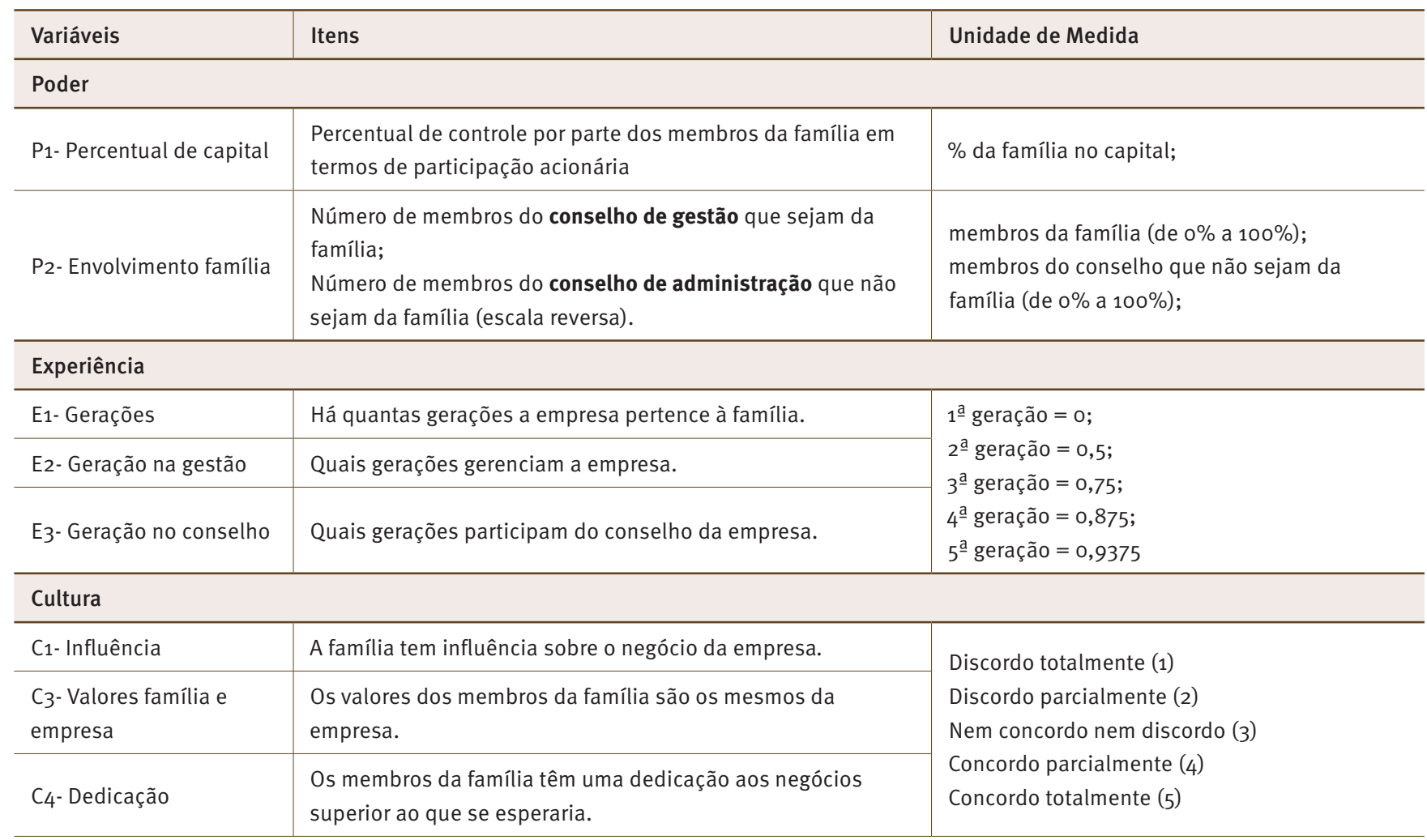

Nota: Adicionamos uma limitação ao nosso estudo quanto à não observação do último elemento de experiência (número de membros da família no negócio), dada a impossibilidade de se chegar a essa informação com precisão em nossa amostra.

Fonte: Klein et al. (2005).

\section{Ciclo de vida das organizações}

O ciclo de vida é uma das variáveis relevantes na discussão do processo sucessório das organizações (Tillmann \& Grzybovski, 2005) e permite entender elementos do modelo de gestão e estratégias por elas adotadas. Baseado na visão das ciências biológicas, leva em conta que as organizações progridem numa sequência de estágios nos quais se pretende distinguir características que essas empresas possam ter ao longo de suas vidas. Dessa maneira, estudos sobre ciclo de vida permitem aos gestores o entendimento das organizações e suas características durante sua trajetória. 
O estudo do ciclo de vida organizacional em empresas familiares é importante pelo fato de poder estar relacionado ao ciclo de vida dos próprios controladores do negócio. Nesse sentido, o ciclo de vida do membro fundador (Gersick et al., 1997), paralelamente ao ciclo de vida da empresa, é algo significativo para a continuidade dos negócios familiares, tendo em vista a transição de poder de geração a geração inerente ao processo sucessório nessas empresas (Peiser \& Wooten, 1983). Além disso, pode-se, por meio do modelo do ciclo de vida, identificar aspectos positivos e negativos relacionados ao desenvolvimento da organização. Por fim, busca-se investigar quais características específicas das empresas familiares caracterizam cada estágio do ciclo de vida, seguindo a linha de estudos que objetivam a caracterização e tipificação de empresas familiares (Dekker et al., 2012; Garcia-Castro \& Casasola, 2011; Nordqvist, Sharma, \& Chirico, 2014; Westhead \& Howorth, 2007).

Existem vários modelos de ciclo de vida com diferentes quantidades de estágios, mas, em geral, apresentam suas configurações levando em conta o contexto organizacional, a estratégia e a estrutura, entre os quais citamos Gordon e Miller (1976), Miller (1984), Quinn e Cameron (1983), Miller e Friesen (1984) e Lester et al. (2003). Nesta pesquisa, foi utilizado o modelo de Lester et al. (2003), pois (i) se aplica a empresas de portes variados (não apenas grande, mas também médio e pequeno portes), (ii) incorpora variáveis complexas apresentadas por outros modelos e (iii) apresenta afinidade com variáveis relacionadas ao controle gerencial, o que leva a organização a se aperceber da demanda por mecanismos, além de estrutura, procedimentos e ritos.

O modelo de Lester et al. (2003) basicamente classifica as organizações em cinco estágios, que são o nascimento, crescimento, maturidade, declínio e rejuvenescimento, derivados dos estudos de Miller e Friesen (1984). Embora não exista expectativa de que a sequência seja sempre seguida, a sua racionalidade é relevante (Hanks, 1990). Na verdade, existem evidências de pulos para a frente e para trás, retornos de empresas aos vários estágios e alguns nunca vivenciados (Lester, Parnell, \& Menefee, 2009).

O modelo foi testado em várias situações e utilizado em perspectivas distintas com o objetivo de ampliar seu poder de explicação (Lester et al., 2003, 2009; Lester \& Parnell, 2008; Frezatti, Relvas, Nascimento, Junqueira, \& Bido, 2010). 0 modelo abrange variáveis que são relevantes para as organizações e que podem assumir diferentes perfis na sua trajetória de vida (Lester \& Parnell, 2008), tais como processo decisório, processamento de informações, procedimentos operacionais, além de itens estruturais como relacionamento hierárquico, distribuição de poder e estrutura organizacional. 0 modelo de Lester et al. (2003) foi aperfeiçoado no que se refere à classificação, mas se afastou da perspectiva econômica de lucratividade, dado que os interesses temporais podem ser distintos. Uma das fragilidades do modelo de Lester et al. (2003), assim como de todos os outros, é que ele ignora estágios intermediários entre os cinco apresentados.

Os elementos considerados no modelo agregam as seguintes perspectivas (Lester et al., 2003):

- Situação: esse elemento se refere às perspectivas gerais da organização, tais como tamanho, idade, diluição de propriedade, locais, mercados atendidos e heterogeneidade;

- Métodos de tomada de decisão: focam os tomadores de decisão;

- Estrutura organizacional: varia de uma pessoa para um conjunto complexo.

- Nascimento: normalmente tem menor porte do que os concorrentes, luta pela existência, processo decisório na mão de poucas pessoas e propriedade concentrada. A gestão é baseada na intuição, e a inovação ocorre de maneira rápida, embora pouco estruturada (Lester \& Parnell, 2008). A estrutura organizacional é simples, com poucas pessoas e baixo nível de receitas. Tende a criar seu próprio ambiente. O grande desafio dos gestores é conseguir clientes e gerar caixa. No que se refere ao processamento de informações, ele é bem simples, quando não é precário. No processo decisório, as informações são mínimas e bem restritas (Moores \& Yuen, 2001). Relatórios contábeis não são encontrados, e o foco é o fluxo de caixa para uma demanda de subsistência. Quando tais relatórios existem, eles são pouco detalhados e não integrados. Cabe destacar que, nesse estágio, a informalidade se sobrepõe à formalidade (Moores \& Yuen, 2001).

- Crescimento: a principal preocupação neste estágio consiste em crescer, e isso proporciona benefício na economia de escala. A estrutura simplificada vai sendo substituída por outra que privilegia o papel dos gestores e a divisão de trabalho, descentralizando as decisões em relação ao estágio anterior. Objetivos 
e metas são estabelecidos (Moores \& Yuen, 2001) primordialmente no que se refere a aspectos que se relacionem com o faturamento. Como consequência, aumenta a necessidade de informações reais para que o uso diagnóstico (comparação entre real e previsto) ocorra, e demanda detalhamento e integração maiores do que na fase do nascimento (Moores \& Yuen, 2001). No que se refere aos sistemas de informações gerenciais, eles sofrem uma grande influência do ciclo de vida (Davila, 2005; Granlund \& Taipaleenmäki, 2005), e a prioridade se volta para informações de elementos ligados a agentes externos. Os gestores dedicam tempo considerável para obter tais informações, já que o processo decisório demanda não apenas maior quantidade, mas informações mais complexas do que no estágio de nascimento (Moores \& Yuen, 2001).

- Maturidade: surgem estruturas mais formais com descrições de funções, relações hierárquicas, políticas e procedimentos que removem muito da flexibilidade e informalidade existentes nos ciclos anteriores. Os gestores no topo da pirâmide dedicam-se à estratégia de planejamento e delegam decisões do dia a dia para níveis hierárquicos inferiores. Existe expectativa de que empresas a partir da maturidade sejam de relativo grande porte (Lester \& Parnell, 2008), embora possa incluir empresas de menor porte que vivenciam baixo crescimento de suas receitas e operam de maneira burocrática com sistemas de informações que enfatizam os controles formais. Muitas organizações neste ciclo têm abundância de caixa. Alguns autores denominaram esta etapa de etapa do sucesso (Lester et al., 2003), porque é um estágio que combina estrutura de controle com potencial de eficiência de produção. Vários estudos evidenciam que, quanto mais se caminha do nascimento para a maturidade, mais os controles de resultados e ações aumentam (Auzair \& LangfieldSmith, 2005; Granlund \& Taipaleenmäki, 2005; Haustein, Luther, \& Schuster, 2014; Moores \& Yuen, 2001). Nesta etapa, a existência da contabilidade proporciona sistemas de relatórios gerenciais, orçamento e outras ferramentas de gestão. A existência de mecanismos preditivos e de controle ex-post nesta etapa é comum, e o afastamento do fundador das operações do dia a dia é uma realidade (Davila, 2005; Haustein et al., 2014). A relativa maior quantidade de proprietários também é uma característica deste estágio (Haustein et al., 2014).
- Declínio: trata-se do estágio em que a organização falhou no confronto com desafios externos. Relativamente, em algum momento, há escassez de recursos e ocorrência de resultados desfavoráveis (Moores \& Yuen, 2001). Esse desempenho desfavorável resulta em queda de resultados financeiros e market share, em muitos casos, devido à ausência de inovação. A situação leva a um foco nos problemas internos e, consequentemente, falta de foco no cliente, trazendo um processo decisório muito centralizado. A luta pelo poder relacionada aos reconhecimentos pessoais por parte da alta administração aparece com destaque neste ciclo (Lester et al., 2003). Miles e Snow (1978) consideram que esse perfil de organização se caracteriza como perfil estratégico reativo, ou seja, não se antecipa às oportunidades e riscos do ambiente. Ainda que o declínio não necessariamente conduza à morte da organização, demanda mudanças na estratégia, estrutura, processo decisório e situação para levá-la a uma configuração mais estável. A morte da organização neste contexto não é tratada pelo referencial teórico adotado. Nesta etapa, constata-se que pode ocorrer o abandono do uso de mecanismos de controle anteriormente implementados (Frezatti et al., 2010) e a concentração em poucos instrumentos, dando preferência a uma abordagem mais informal de gestão (Moores \& Yuen, 2001).

- Rejuvenescimento: pode ocorrer como resposta ao excesso de burocratização e ausência de inovação. 0 grande objetivo deste ciclo é retornar ao ambiente de aprendizado, aumentando suas receitas sem perder market-share. Para atender a esse objetivo de menor burocratização, os mecanismos de times de projetos, task forces e grupos cross-functional são encontrados. A centralização da decisão é trocada por uma abordagem mais descentralizada, focada no cliente e que é facilitada pelos recursos de Tecnologia da Informação (TI) (Moores \& Yuen, 2001). Com a criação de divisões, existe a tendência de concentrar os esforços em um grupo menor de informações, embora sejam disponibilizadas para várias divisões, criadas em função da tendência de atuar em mercados ou negócios diferentes; dessa maneira, a organização demanda mecanismos para descentralizar as decisões do dia a dia e manter centralizadas as decisões estratégicas (Moores \& Yuen, 2001). 
As principais características de cada estágio são interpretadas por meio dos itens apresentados no Quadro 2 (Lester et al., 2003 ):

\section{Quadro 2. Indicadores formativos para a mensuração dos estágios do ciclo de vida}

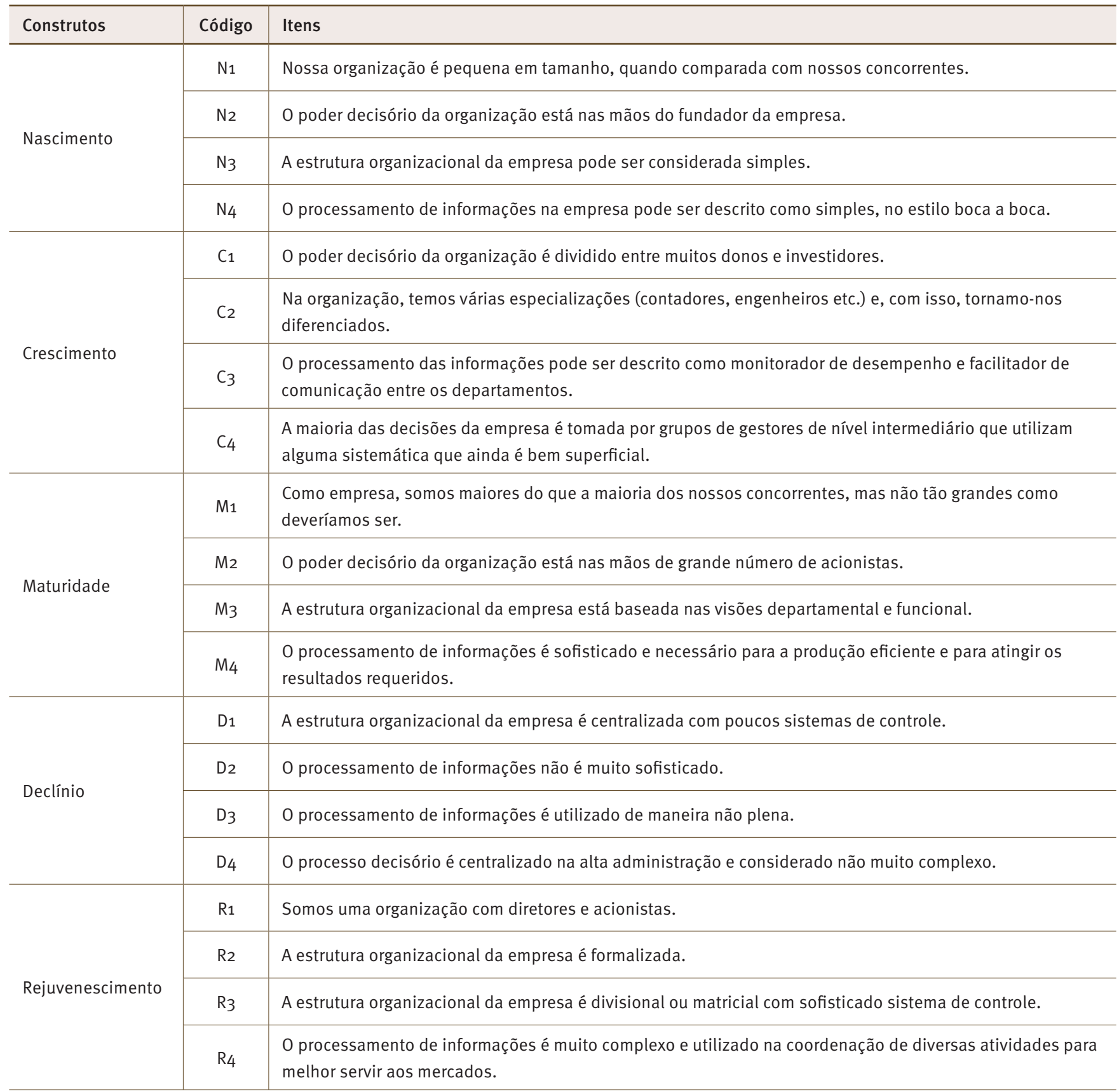

Nota: A escala dos instrumentos é tipo Likert de 5 pontos, sendo 1 discordo totalmente e 5 concordo totalmente.

Fonte: Lester et al. (2003).

Uma dificuldade sempre presente nos estudos de ciclo de vida diz respeito a como classificar as organizações, já que elas podem ter características de vários perfis ao mesmo tempo. Isso se explica porque o modelo tenta enquadrar a organização dentro de cinco possíveis estágios, sem considerar as transições ou subestágios, já que uma organização pode estar parcialmente em um e parcialmente em outro, por exemplo. Dependendo do momento, ela pode até ser totalmente enquadrada em um estágio, mas, num momento seguinte, isso pode não acontecer. 


\section{DESENHO DA PESQUISA}

Como consequência do exposto, o desenho da pesquisa foi estruturado conforme a Figura 2.

Figura 2. Desenho da pesquisa - modelo conceitual

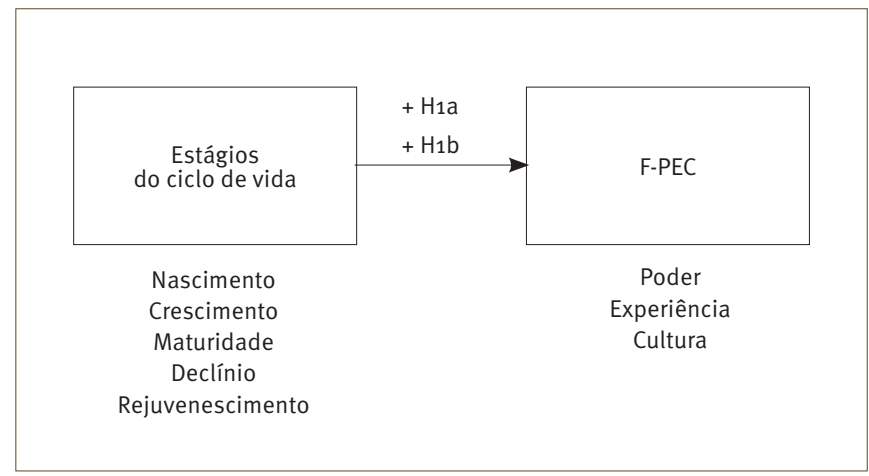

$\mathrm{Na}$ Figura 2, especifica-se a relação entre (i) os construtos do F-PEC e (ii) as variáveis utilizadas por Lester et al. (2003) para caracterizar os estágios do ciclo de vida. A hipótese 1, desdobrada em "a" e "b", foi estabelecida a partir dos referenciais apresentados: "Uma família pode influenciar um negócio a partir da sua propriedade, governança e envolvimento na gestão" (Astrachan et al., 2002, p. 48), assim como a literatura que discutiu a configuração de empresas familiares em relação à perspectiva de sistemas (Gersick et al., 1997; Westhead \& Howorth, 2007), bem como de profissionalização por meio de práticas de gestão (Bedford \& Malmi, 2015; Breton-Miller \& Miller, 2013; Dekker et al., 2012). 0 artigo trata do impacto que os membros da família trazem para a organização por meio dos elementos do F-PEC.

Segundo Chrisman, Chua e Zahra (2003), "No nível mais básico, o que diferencia uma empresa familiar de outras com finalidade de gerar lucros é a influência significativa da família na tomada de decisões e nas operações da empresa" (p. 359). Dessa maneira, graças ao controle, a família torna-se o fator que distingue as organizações, e esse envolvimento é percebido no dia a dia das operações e no processo decisório.

Conforme discutido nos modelos de ciclo de vida organizacional, empresas nos estágios de nascimento e crescimento têm estrutura organizacional e processamento de informações mais simples que nos estágios seguintes, e o processo decisório é mais centralizado nas mãos do fundador, que normalmente é o único acionista do negócio (Greiner, 1972; Lester et al., 2003). Nesse sentido, para esses estágios, espera-se que o poder da família seja significativo (em termos de concentração acionária e participação na gestão) e a cultura familiar esteja mais presente no negócio (comprometimento da família no negócio), devido à presença do fundador e de membros da família na gestão (Breton-Miller \& Miller, 2013; Gersick et al., 1997; Giovannoni, Maraghini, \& Riccaboni, 2011). Por outro lado, espera-se que essas empresas ainda estejam na primeira geração e não tenham passado por processo de sucessão.

Segundo a literatura de ciclo de vida organizacional (Greiner, 1972; Lester et al., 2003) e de empresas familiares (Westhead \& Howorth, 2007), nos estágios de maturidade, as características de empresa familiar tornam-se cada vez mais atenuadas. Isso porque o ciclo normal é essas empresas agregarem novos sócios e executivos externos da família, adotarem gestão mais profissionalizada (Breton-Miller \& Miller, 2013; Giovannoni et al., 2011) e perderem, em certo grau, as características distintivas de empresa familiar. Mas será que essa realidade pode ser extrapolada para o ambiente brasileiro? Nesse sentido, no ambiente brasileiro, o poder e a cultura da família no negócio tendem a permanecer positivamente associados aos estágios de gerações de maturidade, rejuvenescimento e declínio (Andrade et al., 2004; Grzybovski \& Vieira, 2012). Nos estágios mais avançados, as empresas adotam procedimentos formais de tomada de decisões, descentralizam as decisões, e podem diluir o capital visando a realização de investimentos e incluir executivos de fora da família para ocupar posições-chave na empresa (Oliveira et al., 2012). Por fim, espera-se que, nos estágios mais avançados, estejam empresas mais maduras em termos de idade e que já experimentaram o processo de sucessão, pelo qual a empresa acumula experiência ao longo do tempo.

As pesquisas anteriores indicam a existência de associação entre poder, experiência e cultura com o ciclo de vida. Como consequência, a hipótese 1, desdobrada em 1a e 1b, foi estabelecida:

1.a. Existe associação positiva entre os estágios de ciclo de vida organizacional do nascimento e do crescimento e os elementos de poder e cultura do F-PEC;

1.b. Existe associação positiva entre os estágios de vida organizacional da maturidade, do declínio e do rejuvenescimento e os elementos experiência e cultura do F-PEC.

\section{PROCEDIMENTOS METODOLÓGICOS}

Para alcançar o objetivo proposto no artigo, foi aplicado um survey com executivos dessas empresas. Nesse sentido, os 
procedimentos metodológicos abrangem a definição da população e amostra, o instrumento de coleta e suas medidas, e os procedimentos de análise dos dados.

Atualmente, no Brasil, não há um banco de dados que disponha de informações sobre as empresas familiares, inclusive pelo fato de não haver uma delimitação clara sobre em que consiste uma empresa familiar. Dessa maneira, para a coleta de dados, realizou-se um levantamento. A seleção das empresas para envio da pesquisa adotou os seguintes procedimentos: (i) acesso às empresas listadas na Revista Exame Maiores $e$ Melhores; (ii) remoção das empresas governamentais, instituições financeiras e demais empresas listadas na Bolsa de Mercadorias e Futuros Bovespa (BM\&FBovespa), assim como a exclusão de empresas de controle estrangeiro; (iii) envio da pesquisa a 917 empresas que potencialmente se alinham à definição de empresa familiar (Westhead \& Cowling, 1998). As empresas pesquisadas caracterizam-se como de médio e grande portes, utilizando a determinação do Serviço Brasileiro de Apoio às Micro e Pequenas Empresas (Sebrae, 2013) de empresas com mais de 100 funcionários e/ou faturamento/ano superior a $\mathrm{R} \$ 30$ milhões.

Os respondentes da pesquisa são profissionais tanto da família quanto de fora dela, sendo eles, em sua maioria, diretores e gestores da área financeira ou de controladoria da empresa. Foram recebidos 128 questionários, $14 \%$ do total da população, coletados entre novembro de 2013 e junho de 2014, e foram considerados válidos para esta pesquisa 117. Cabe destacar que os resultados do survey referem-se à amostra e não podem ser generalizados para a população.

O percentual de executivos da família na gestão do negócio foi mensurado por meio do número de familiares compondo o conselho de administração ou, quando inexistente, a diretoria executiva. A partir desses percentuais, o maior foi considerado indicativo da participação da família na gestão do negócio. Em relação ao estágio geracional, perguntou-se quais gerações são controladoras do negócio; destas, determinou-se a geração mais antiga para indicar o estágio geracional da empresa. Por fim, a idade foi calculada a partir da data de fundação da organização.

As assertivas do modelo do ciclo de vida (Lester et al., 2003) foram traduzidas e aplicadas em vários trabalhos no Brasil, sendo adaptadas. Analogamente, as assertivas do modelo do F-PEC (Astrachan et al., 2002) também passaram pelo mesmo processo. A escala utilizada para os instrumentos é tipo Likert, sendo 1 para discordo totalmente e 5 para concordo totalmente. Os Quadros 1 e 2 apresentam os construtos e as respectivas escalas e variáveis utilizadas.

Em ambos os casos, foram realizados pré-testes com dois executivos de empresa e dois docentes da área de controle gerencial, identificando esclarecimentos e sugestões sobre fidelidade do que se pretendia captar.

Os dados foram analisados por meio de estatísticas descritivas e modelagem de equações estruturais com estimação por mínimos quadrados parciais (Hair Jr., Hult, Ringle, \& Sarstedt, 2014), que foi considerado o método mais adequado por permitir o teste das hipóteses quando se têm variáveis latentes, inclusive modelos formativos (Diamantopoulos, Riefler, \& Roth, 2008), que é o caso da presente pesquisa. O software utilizado foi o SmartPLS v.324 (Ringle, Wende, \& Becker, 2015).

\section{TRATAMENTO E ANÁLISE DOS DADOS}

São apresentadas as análises dos dados demográficos com base na classificação das empresas, características de idade, participação da família na gestão e geração no controle na empresa que prevalecem em cada ciclo de vida.

\section{Análise dos dados demográficos}

No que se refere às questões demográficas da pesquisa, podem ser percebidas as concentrações de empresas em alguns setores (varejo, bens de consumo e energia, na Tabela 1). Em termos de impacto, a concentração de setores proporciona perfil de empresas de maior porte (bens de consumo e energia) e empresas de menor porte (varejo).

\section{Tabela 1. Distribuição das empresas em setores}

\begin{tabular}{l|c|c}
\hline Setor & $\mathbf{n}$ & $\%$ \\
\hline Varejo & 29 & $23 \%$ \\
\hline Bens de consumo & 13 & $10 \%$ \\
\hline Energia & 12 & $9 \%$ \\
\hline Atacado & 9 & $7 \%$ \\
\hline Produção agropecuária & 9 & $7 \%$ \\
\hline Indústria da construção & 8 & $6 \%$ \\
\hline Têxteis & 7 & $5 \%$ \\
\hline Bens de capital & 5 & $4 \%$ \\
\hline Siderurgia e metalurgia & 5 & $4 \%$ \\
\hline Transporte & 5 & $4 \%$ \\
\hline Diversos & 15 & $13 \%$ \\
\hline Total & 117 & $100 \%$ \\
\hline
\end{tabular}


A existência de grande quantidade de funcionários proporciona um viés de porte e complexidade para o perfil da pesquisa, evidenciado na Tabela 2. 0 porte da organização pode ser considerado um fator relevante para a existência de uma estrutura organizacional complexa, com poder decisório descentralizado e com processamento de informações por meio de sistemas formais e complexos característicos de um estágio de ciclo de vida posterior ao de crescimento.
Tabela 2. Distribuição das empresas pela quantidade de funcionários

\begin{tabular}{l|c|c}
\hline Número de colaboradores & \multicolumn{2}{|c}{ Quant. de empresas } \\
\hline Mais de 1.000 & 60 & $51 \%$ \\
\hline Entre 501 e 1.000 & 22 & $19 \%$ \\
\hline Até 500 & 35 & $30 \%$ \\
\hline Total & 117 & $100 \%$ \\
\hline
\end{tabular}

A amostra tem uma distribuição etária (Tabela 3) razoavelmente dispersa, pois constam empresas de vários perfis, embora predominem aquelas com mais de 25 anos de existência, o que caracteriza longevidade e experiência das organizações.

\section{Tabela 3. Análise descritiva por estágio do ciclo de vida}

\begin{tabular}{|c|c|c|c|c|c|c|c|}
\hline & $\mathrm{N}$ & $\mathrm{C}$ & $M$ & D & $\mathbf{R}$ & $\mathrm{ENC}^{*}$ & Total \\
\hline Até 50\% & 0 & o & 0 & 5 & 1 & 2 & 8 \\
\hline Entre $50,1 \%$ e $99,9 \%$ & 0 & 1 & 1 & 15 & 3 & 4 & 24 \\
\hline $100 \%$ & 10 & 6 & 8 & 28 & 17 & 16 & 85 \\
\hline \multicolumn{8}{|l|}{ \% família na gestão } \\
\hline Até 50\% & 7 & 3 & 3 & 22 & 11 & 9 & 55 \\
\hline Entre $50,1 \%$ e $99,9 \%$ & 1 & 2 & 2 & 15 & 4 & 6 & 30 \\
\hline $100 \%$ & 2 & 2 & 4 & 11 & 6 & 7 & 32 \\
\hline Geração 2 & 4 & 1 & 2 & 25 & 4 & 10 & 46 \\
\hline Geração 3 & 1 & 4 & 7 & 9 & 6 & 6 & 33 \\
\hline Geração 4 & 0 & 0 & 0 & 1 & 1 & 1 & 3 \\
\hline Geração 5 & 0 & 0 & 0 & 0 & 1 & 0 & 1 \\
\hline \multicolumn{8}{|l|}{ Idade* $^{*}$} \\
\hline De o a 10 anos & 3 & 1 & 0 & 3 & 2 & 4 & 13 \\
\hline De 11 a 20 anos & 0 & 1 & 0 & 4 & 2 & 1 & 8 \\
\hline De 21 a 30 anos & 2 & 1 & 1 & 6 & 3 & 3 & 16 \\
\hline
\end{tabular}

Nota: Nascimento (N), Crescimento (C), Maturidade (M), Declínio (D) e Rejuvenescimento (R), Empresa não classificada (ENC)

* Calculado com ano 2014 menos a data de fundação. 0 ano de 2014 foi quando a pesquisa foi realizada.A predominância de empresas com duas e três gerações mostrase na pesquisa, indicando que a experiência da família com a empresa é uma realidade (Tabela 3). Além disso, temos um número significativo de empresas na primeira geração, em que o fundador tende a exercer um papel fundamental na gestão do negócio, o que pode estar associado a um ciclo de vida de nascimento, ou seja, com poder decisório centralizado e estrutura organizacional simples. 
Além das frequências que remetem à idade e porte da empresa apresentadas anteriormente, procuramos identificar associações entre os estágios do ciclo de vida e determinadas características da empresa, como o percentual de executivos da família na gestão do negócio, estágio geracional na gestão do negócio e idade do negócio. Essa análise poderia contribuir para a discussão da hipótese de pesquisa (Tabela 3 ).

Para a determinação do estágio de ciclo de vida, foi determinada a categoria (estágio de ciclo de vida) com pontuação mais alta. Esse critério foi utilizado por Lester et al. (2009). Isso ocorreu porque todos os respondentes indicaram o perfil de sua organização considerando todos os fatores e foram percebidas classificações com equilíbrio entre nascimento e crescimento, por exemplo. A classificação das empresas, para fins de comparação, foi desenvolvida da seguinte maneira: se a média de determinado respondente é 3 para o estágio 1; 4 para o estágio 2; 5 para o estágio 3; 2 para o estágio 4; e 3 para o estágio 5 , a empresa foi classificada como estando no estágio 3. Por meio dessa classificação, verificaram-se empresas com pontuações altas iguais para estágios diferentes, e para esses casos optou-se por não eliminar da amostra essas empresas, mas, sim, apresentá-las em separado (empresa não classificada - ENC). Com base na classificação proposta, podemos verificar que a maioria das empresas na nossa amostra está no estágio de declínio.

Além disso, é possível ver que a maioria das empresas no estágio de nascimento possui menor participação da família na gestão, enquanto empresas na maturidade e no declínio possuem uma alta participação da família na gestão. Esse resultado contrapõe de certa forma a literatura, segundo a qual se esperaria um perfil diferente em relação à participação da família na gestão (Hiebl, Duller, Feldbauer-Durstmüller, \& Ulrich, 2015; Speckbacher \& Wentges, 2012; Zahra, Neubaum, \& Larrañeta, 2007).

Acontece que as empresas no nascimento, além de serem relativamente mais jovens, podem contar com participações de investidores, o que altera o modelo em que têm influência da família no conselho de administração ou conselho de gestão. Quanto às gerações, a Tabela 4 apresenta resultados condizentes com a literatura em que empresas no nascimento se concentram nas primeiras gerações (Breton-Miller \& Miller, 2013; Gersick et al., 1997; Westhead \& Howorth, 2007) e, nos outros estágios do ciclo de vida, apresenta-se um comportamento mais disperso. Ao analisar a idade do negócio, verificamos que a relação dos estágios do ciclo de vida com a idade não é tão linear (BretonMiller \& Miller, 2013), e não é possível constatar uma associação clara. Já Morais e Silva (2014) apontam que a maioria das empresas industriais na sua amostra está na fase de coordenação (com base no modelo de Greiner), mas não identificam associações estatisticamente significantes em relação às dimensões de idade e tamanho da empresa. Essa discussão preliminar será aprofundada com a análise do modelo de equações estruturais que é apresentada na sequência, tendo em vista que, ao adotar a classificação, obtivemos uma concentração das empresas no estágio de declínio e rejuvenescimento.

\section{Avaliação do modelo de mensuração}

Com o objetivo de discutir a hipótese de pesquisa, foi realizada a análise por modelagem de equações estruturais, em que os construtos do F-PEC e os estágios do ciclo de vida foram considerados variáveis latentes do modelo estrutural. A partir dessa análise, é possível discutir o relacionamento entre as dimensões, por meio da significância e tamanho dos coeficientes estruturais, complementando as análises da seção anterior.

As características das empresas familiares mensuradas pelas dimensões do F-PEC (cultura, experiência e poder) foram modeladas como construtos reflexivos e apresentaram validade convergente (AVE > 0,5), validade discriminante (raiz quadrada da AVE maior que as correlações entre as variáveis latentes) e confiabilidade superior a o,7 (Tabela 4). Esses critérios são recomendados em diversos referenciais metodológicos, por exemplo, por Hair Jr. et al. (2014).

O modelo de Lester et al. (2003) contém quatro questões para cada ciclo, abrangendo aspectos de estrutura, tomada de decisões, processamento de informações e procedimentos operacionais (Lester \& Parnell, 2008). Como os indicadores usados para mensurar cada estágio são complementares e determinantes do estágio do ciclo de vida (Lester et al., 2003), eles foram modelados como indicadores formativos (Diamantopoulos et al., 2008; Hair Jr. et al., 2014) no modelo de equações estruturais.

A análise dos construtos reflexivos indica que os três elementos, poder, experiência e cultura, afetam de maneiras distintas as etapas do ciclo de vida das organizações. A análise dos construtos formativos apresentará os elementos de maneira detalhada.

\section{Análise dos resultados e discussão}

O modelo estrutural tem por objetivo associar a presença da família com o ciclo de vida da organização, por meio das dimensões poder, experiência e cultura. Pode-se comentar a influência da família nas organizações, de acordo com o estágio do ciclo de vida (Tabela 5). 
Tabela 4. Matriz de correlações entre as variáveis latentes

\begin{tabular}{|c|c|c|c|c|c|c|c|c|}
\hline Variáveis latentes & 1 & 2 & 3 & 4 & 5 & 6 & 7 & 8 \\
\hline 1 - Cultura familiar & 1 & & & & & & & \\
\hline 2 - Experiência família gestão & $-0,133$ & 1 & & & & & & \\
\hline 3 - Poder familiar na gestão & 0,048 & 0,162 & 1 & & & & & \\
\hline 4-Nascimento & 0,094 & $-0,456$ & $-0,265$ & 1 & & & & \\
\hline 5-Crescimento & 0,190 & 0,043 & 0,124 & $-0,186$ & 1 & & & \\
\hline 6 - Maturidade & 0,367 & $-0,293$ & $-0,000$ & 0,074 & $-0,075$ & 1 & & \\
\hline 7 - Rejuvenescimento & 0,257 & $-0,152$ & 0,227 & 0,086 & 0,166 & 0,184 & 1 & \\
\hline Variância média extraída & 0,693 & 0,588 & 1 & & & & & \\
\hline Confiabilidade composta & 0,817 & 0,804 & 1 & & & & & \\
\hline
\end{tabular}

Nota 1: Correlações superiores a $|0.181|$ são significantes a $5 \%$ e correlações superiores a $|0.237|$ são significantes a 1\%. As células cinzas são as correlações mais altas. Nota 2: Foram excluídos dois indicadores por apresentarem baixa carga fatorial (descrição no Quadro 1): P1 - Percentual de capital e $C_{1}$ - Influência.

Tabela 5. Coeficientes estruturais associando F-PEC aos estágios do ciclo de vida

\begin{tabular}{|c|c|c|c|c|c|c|}
\hline Hipóteses & $\begin{array}{l}\text { Coefic. } \\
\text { Estrut. }\end{array}$ & $\begin{array}{c}\text { Erro } \\
\text { padrão }\end{array}$ & Valor-t & Valor-p & $\mathbf{R}^{2}$ & $\begin{array}{c}\mathbf{R}^{2} \\
\text { ajustado }\end{array}$ \\
\hline Cultura familiar $->$ Nascimento & 0,048 & 0,136 & 0,351 & 0,726 & \multirow{3}{*}{0,248} & \multirow{3}{*}{0,228} \\
\hline Experiência_família_gestão -> Nascimento & $-0,417$ & 0,089 & 4,667 & 0,000 & & \\
\hline Poder_familiar_na_gestão -> Nascimento & $-0,200$ & 0,097 & 2,070 & 0,039 & & \\
\hline Poder_familiar_na_gestão -> Crescimento & 0,106 & 0,171 & 0,623 & 0,534 & 0,052 & 0,027 \\
\hline Cultura familiar $->$ Maturidade & 0,332 & 0,110 & 3,019 & 0,003 & \multirow[b]{2}{*}{0,196} & \multirow[b]{2}{*}{0,175} \\
\hline Experiência_família_gestão -> Maturidade & $-0,253$ & 0,137 & 1,838 & 0,066 & & \\
\hline Cultura familiar -> Rejuvenescimento & 0,224 & 0,139 & 1,614 & 0,107 & \multirow{3}{*}{0,137} & \multirow{3}{*}{0,114} \\
\hline Experiência_família_gestão -> Rejuvenescimento & $-0,162$ & 0,218 & 0,743 & 0,458 & & \\
\hline Poder_familiar_na_gestão $->$ Rejuvenescimento & 0,242 & 0,146 & 1,662 & 0,096 & & \\
\hline Cultura familiar -> Declínio & 0,044 & 0,236 & 0,186 & 0,853 & \multirow{3}{*}{0,107} & \multirow{3}{*}{0,083} \\
\hline Experiência_família_gestão -> Declínio & $-0,315$ & 0,210 & 1,495 & 0,135 & & \\
\hline Poder_familiar_na_gestão -> Declínio & $-0,019$ & 0,138 & 0,140 & 0,889 & & \\
\hline
\end{tabular}

Nota: Valores-p estimados a partir de bootstrap com 5.000 reamostras e opção construct level changes. 
Os detalhes desses achados são:

Hipótese 1a.: Existe associação positiva entre os estágios de ciclo de vida organizacional do nascimento e do crescimento e os elementos de poder e cultura do F-PEC;

A hipótese 1a foi parcialmente validada (Quadro 3):

\section{Quadro 3. Resumo dos achados da hipótese 1a}

\begin{tabular}{l|l|l}
\hline Descrição & Nascimento & Crescimento \\
\hline Poder & $\begin{array}{l}\text { Validada com sinal } \\
\text { negativo }\end{array}$ & $\begin{array}{l}\text { Não houve } \\
\text { validação } \\
\text { estatística }\end{array}$ \\
\hline Cultura & $\begin{array}{l}\text { Não houve } \\
\text { validação } \\
\text { estatística }\end{array}$ & $\begin{array}{l}\text { Não houve } \\
\text { validação } \\
\text { estatística }\end{array}$ \\
\hline
\end{tabular}

- No que se refere ao estágio do nascimento, foi obtido: As variáveis que apresentaram significância estatística $(p<0,05)$ foram poder e experiência, com poder explicativo de $22,8 \%$, o que se mostra relevante para estudos similares (Cohen, 1988). O sinal de ambas as variáveis é negativo, o que implica dizer que: (i) quanto menor a proporção de pessoas da família no negócio, maior a identificação com o nascimento, e (ii) quanto menor a experiência, maior a identificação com as características do estágio de nascimento.

Pela análise descritiva, mostramos que as empresas nos estágios de nascimento e crescimento, como seria de se esperar, são as relativamente mais jovens, seguidas pelas empresas nos estágios de maturidade e declínio, em sua maioria acima de 40 anos. Já o estágio de rejuvenescimento apresenta certa dispersão quanto à idade das organizações. Quanto ao percentual de executivos da empresa que fazem parte do conselho de gestão ou do conselho de administração, pode-se dizer que, no estágio de maturidade, a maior parte do conselho é composta por executivos da família, assim como no estágio de declínio. Nos demais estágios do ciclo de vida organizacional, essa característica apresenta certa dispersão.

Seria esperado que empresas com o fundador na gestão do negócio e exclusivamente com executivos da família (Gersick et al., 1997) fossem mais encontradas nos ciclos de vida iniciais, como nascimento e crescimento, tendo em vista o seu modelo de gestão e o nível de aplicação das práticas de gestão (BretonMiller \& Miller, 2013; Dekker et al., 2012).

0 primeiro resultado, perceptível a partir da Tabela 5, indica que a participação da família na gestão é relacionada negativamente às características do estágio de nascimento. Esse achado não se mostrou consistente com a literatura (Breton-Miller
\& Miller, 2013; Hiebl et al., 2015; Speckbacher \& Wentges, 2012; Zahra et al., 2007), onde essa característica não seria esperada. Esse resultado pode ser explicado pelo porte das empresas que compõem a amostra da presente pesquisa, ou seja, embora esteja no estágio do nascimento, a maioria das empresas não é de pequeno porte. Dessa maneira, o que seria de esperar em termos de participação da família não se mostra da mesma forma em empresas de pequeno porte, em que a família teria participação maior. Speckbacker e Wentges (2012) identificaram o porte como uma variável moderadora importante para o relacionamento entre influência da família e práticas de gestão.

0 segundo resultado é consistente com a literatura, pois se espera que empresas com as primeiras gerações da família no negócio estejam associadas ao estágio do ciclo de vida do nascimento, no qual a experiência é relativamente menor do que nas outras gerações e, em decorrência, nos outros estágios. Esse resultado é consistente com a classificação de "empresas de família fundadora" (Breton-Miller \& Miller, 2013), bem como com o modelo autocrático de gestão (Dekker et al., 2012).

- Quanto ao estágio do crescimento

As dimensões do F-PEC, no que se refere à amostra desta pesquisa, não apresentaram significância estatística $(p>0,10)$ com o estágio de crescimento. Em relação à geração da família controladora do negócio, pode-se dizer que as empresas em crescimento apresentam predominância da terceira geração.

Hipótese 1.b.: Existe associação positiva entre os elementos experiência e cultura e os estágios de vida organizacional na maturidade, no declínio e no rejuvenescimento.

A hipótese 1 b foi parcialmente validada (Quadro 4):

Quadro 4. Resumo dos achados da hipótese 1b

\begin{tabular}{l|l|l|l}
\hline Descrição & Maturidade & Declínio & Rejuvenescimento \\
\hline Poder & $\begin{array}{l}\text { Não previsto } \\
\text { na hipótese }\end{array}$ & $\begin{array}{l}\text { Não } \\
\text { previsto na } \\
\text { hipótese }\end{array}$ & $\begin{array}{l}\text { Validada embora } \\
\text { não tenha } \\
\text { referencial que } \\
\text { preveja }\end{array}$ \\
\hline Experiência & $\begin{array}{l}\text { Validada com } \\
\text { sinal negativo }\end{array}$ & $\begin{array}{l}\text { Não houve } \\
\text { validação } \\
\text { estatística }\end{array}$ & Não validada \\
\hline Cultura & Validada & $\begin{array}{l}\text { Não houve } \\
\text { validação } \\
\text { estatística }\end{array}$ & Validada \\
\hline
\end{tabular}


- Em termos de estágio da maturidade

As variáveis destacadas e que apresentaram significância estatística $(p<0,10)$ nesta etapa são a cultura e a experiência, com poder explicativo de $17,5 \%$ da variância do estágio de maturidade, patamar considerado relevante para estudos similares (Cohen, 1988). No que se refere à experiência, apresenta coeficiente negativo, o que indica que a sequência das gerações, variável relevante nesse construto, pode ter diferentes impactos. Um efeito importante é que, quanto mais as gerações se sucedem, menor a possibilidade de a empresa se manter na maturidade, o que muda a expectativa de sinal constantemente positivo. O trabalho de Holt, Rutherford e Kuratko (2010) indica que o benefício da experiência declina com o avanço das gerações. Esse resultado está em consonância com o argumento de limitação de determinismo e/ou subjetividade do ciclo de vida, em que uma empresa familiar jovem pode apresentar sinais de uma com mais idade (Grzybovski \& Vieira, 2012).

No que se refere à cultura, o resultado indica que os valores da família estão impregnados na empresa, bem como existe a dedicação dos familiares à organização, e isso é refletido no sinal do coeficiente, que é positivo.

A questão da cultura na gestão da empresa pode trazer influência sobre o modelo de gestão adotado. Podemos fazer referência ao tipo de empresa tratado por Dekker et al. (2012) como administrativa híbrida em que, apesar de haver uma alta influência da família no negócio, a empresa apresenta processos formalizados de gestão (como controles financeiros e orçamento) e estrutura hierárquica definida. Apesar disso, os resultados contrapõem de certa forma Speckbacher e Wentges (2012) e Hiebl et al. (2015), os quais esperam que empresas com característica familiar apresentem controles informais de gestão e comunicação de modo preponderante.

- No que se refere ao estágio de declínio

Nenhuma dimensão do F-PEC apresentou significância estatística $(p>0,10)$ com este estágio.

Em relação à geração da família controladora do negócio, pode-se dizer que as empresas em declínio abrangem empresas da segunda geração. De acordo com Holt et al. (2010), o benefício da experiência declina com o avanço das gerações.

- Quanto ao estágio do rejuvenescimento

O poder e a cultura apresentaram significância estatística de p<o,11; em ambos os casos, com sinal positivo nos coeficientes. 0 poder explicativo do modelo é de $11,4 \%$, que pode ser considerado um tamanho de efeito médio (Cohen, 1988). No que se refere ao poder, indica que a maior participação da família na gestão e controle é relevante e, no caso da cultura, a dedicação da família e os valores compartilhados são relevantes para o estágio de rejuvenescimento. Cabe destacar que o estágio de rejuvenescimento pode suceder quaisquer outros dos estágios do ciclo de vida organizacional, além do declínio (Lester et al., 2003). Já em relação à geração da família controladora do negócio, pode-se dizer que as empresas em rejuvenescimento detêm controladores da primeira e segunda gerações da família.

\section{CONCLUSÕES}

A questão estabelecida nesta pesquisa, em que se analisa a relação entre os estágios do ciclo de vida (nascimento, crescimento, maturidade, declínio e rejuvenescimento) e as características das empresas familiares (poder, experiência e cultura), levou em conta uma amostra de 117 empresas brasileiras, sem a inclusão de empresas com ações negociadas em bolsa de valores.

Partindo de um estudo exploratório, o que pode ser inferido é que, embora os três elementos do F-PEC sejam identificados nos vários estágios, em cada um deles, seu impacto e relevância podem ser diferentes como caracterizadores e, provavelmente, como estimuladores para que a organização se movimente para outro estágio ou mesmo para que se defina como presente em um dado estágio de maneira estável e praticamente permanente. Dada a abordagem desenvolvida, não se pretende propor uma relação causal entre elas, mas explicitar a associação identificada, o que deve ser estimulador de outras pesquisas.

Os três elementos do F-PEC estão associados diferentemente, em termos de tamanho do efeito ou sinal, com cada estágio do ciclo de vida organizacional. Isso indica que o modelo de ciclo de vida pode ser considerado limitado quando se trata de empresas familiares, em que os elementos poder, cultura e experiência estão presentes diferentemente em cada estágio. Dessa forma, os seguintes aspectos surgem como elementos de discussão e demanda por pesquisas: (i) porte e estágio e (ii) experiência e profissionalização

O porte sempre foi colocado como divisor de águas no estágio do ciclo de vida nascimento. Na pesquisa, o questionamento a ser colocado é que, embora tenham porte significativo, existem empresas no ciclo do nascimento, o que provoca reflexão direcionada à revisão de modelos, no sentido de buscar tanto a identificação de subciclos como variáveis que possam refletir peculiaridades. Por sua vez, quanto às variáveis relacionadas com experiência (sucessões de gerações) e maturidade (movimentação para a profissionalização), os resultados obtidos estimulam uma pergunta a ser respondida por outra pesquisa: A sucessão de gerações (permanência 
de participantes da família) caminha no sentido contrário à profissionalização (profissionais externos à família)?

O elemento poder, contraditoriamente à literatura, está associado negativamente ao estágio de nascimento e positivamente ao de rejuvenescimento. 0 elemento experiência é associado negativamente aos estágios de nascimento e maturidade, ou seja, empresas que já passaram por processos de sucessão têm menor tendência de apresentar essas características, o que está alinhado à literatura, ao olharmos para o estágio de nascimento. Por fim, verifica-se que o elemento cultura da família está associado positivamente aos estágios considerados de transição e de estabilidade da empresa, respectivamente, rejuvenescimento e maturidade, o que indica que a perspectiva do comprometimento e visão da família possuem uma característica mais permanente e longeva.

A contribuição da pesquisa está ligada ao entendimento dos diferentes elementos característicos da vida organizacional das empresas familiares e de como esses elementos podem ser utilizados em termos de planejamento de migração para estágios mais desejáveis, como crescimento, maturidade e rejuvenescimento.

\section{Limitações}

O ciclo de vida está relacionado ao tempo e ao porte de empresa e, porque a amostra abrange empresas de médio e grande portes, e mesmo empresas com décadas de existência, tais características podem ter influenciado os resultados do modelo de equações estruturais. Considere-se que grande parte dos estudos de ciclo de vida abrangia empresas com uma heterogeneidade de tamanho e de idade expressiva. Por fim, como já foi destacado, a amostra não é aleatória, portanto as conclusões não são generalizáveis estatisticamente, mas nos auxiliaram a aprofundar nosso entendimento do fenômeno sob estudo.

\section{REFERÊNCIAS}

Andrade, D. M., Grzybovski, D., \& Lima, J. B. de. (2004). Aplicabilidade do "modelo dos três círculos" em empresas familiares brasileiras: Um estudo de caso. Revista Eletrônica de Administração, 11(5), 2-25.

Astrachan, J. H., Klein, S. B., \& Smyrnios, K. X. (2002). The F-PEC scale of family influence: A proposal for solving the family business definition problem. Family Business Review, 15(1), 45-58. doi:10.1111/j.1741$6248.2002 .00045 \cdot x$

Auzair, S. M., \& Langfield-Smith, K. (2005). The effect of service process type, business strategy and life cycle stage on bureaucratic MCS in service organizations. Management Accounting Research, 16(4), 399-421. doi:10.1016/j.mar.2005.04.003
Barnett, T., Long, R. G., \& Marler, L. E. (2012). Vision and exchange in intra-family succession: Effects on procedural justice climate among nonfamily managers. Entrepreneurship Theory and Practice, 36(6), 1207-1225. doi:10.1111/j.1540-6520.2012.00546.x

Bedford, D. S., \& Malmi, T. (2015). Configurations of control: An exploratory analysis. Management Accounting Research, 27, 2-26. doi:10.1016/j.mar.2015.04.002

Berrone, P., Cruz, C., \& Gómez-Mejía, L. R. (2012). Socioemotional wealth in family firms: Theoretical dimensions, assessment approaches, and agenda for future research. Family Business Review, 25(3), 258 279. doi:10.1177/0894486511435355

Bertucci, J. L. O., Campos, E. Á. S., Pimentel, T. D., \& Pereira, R. D. (2009). Mecanismos de governança e processos de sucessão: Um estudo sobre a influência dos elementos da governança corporativa na orientação do processo sucessório em uma empresa familiar. Revista Brasileira de Gestão de Negócios, 11(31), 152-167.

Breton-Miller, I. Le, \& Miller, D. (2013). Socioemotional wealth across the family firm life cycle: A commentary on "family business survival and the role of Boards". Entrepreneurship Theory and Practice, 37, 1391-1397. doi:10.1111/etap.12072.

Breton-Miller, I. Le, Miller, D., \& Lester, R. H. (2011). Stewardship or agency? A social embeddedness reconciliation of conduct and performance in public family businesses. Organization Science, 22(3), 704-721. doi:10.1287/orsc.1100.0541

Cançado, V. L., Lima, J. B. de, Muylder, C. F. de, \& Castanheira, R. B. (2013). Ciclo de vida, sucessão e processo de governança em uma empresa familiar: Um estudo de caso no Grupo Seculus. Revista Eletrônica de Administração, 19(2), 485-516.

Chrisman, J. J., Chua, J. H., \& Sharma, P. (2005). Trends and directions in the development of a strategic management theory of the family firm. Entrepreneurship Theory and Practice, 29(5), 555-576. doi:10.1111/ j.1540-6520.2005.00098.x

Chrisman, J. J., Chua, J. H., \& Zahra, S. A. (2003). Creating wealth in family firms through managing resources: Comments and extensions. Entrepreneurship Theory and Practice, 27(4), 359-365. doi:10.1111/1540-8520.to1-1-00014

Chua, J. H., Chrisman, J. J., \& Sharma, P. (1999). Defining the family business by behavior. Entrepreneurship: Theory and Practice, 23(4), 19-39.

Cohen, J. (1988). Statistical power analysis for the behavioral sciences (2nd ed.). New York, USA: Psychology Press.

Davila, T. (2005). An exploratory study on the emergence of management control systems: Formalizing human resources in small growing firms. Accounting, Organizations and Society, 30(3), 223-248. doi:10.1016/j. aos.2004.05.006

Dawson, A., \& Mussolino, D. (2014). Exploring what makes family firms different: Discrete or overlapping constructs in the literature? Journal of Family Business Strategy, 5(2), 169-183. doi:10.1016/j. jfbs.2013.11.004

Debicki, B. J., Matherne, C. F., Kellermanns, F. W., \& Chrisman, J. J. (2009). Family business research in the new millennium: An overview of the who, the where, the what, and the why. Family Business Review, 22(2), 151-166. doi:10.1177/0894486509333598

Dekker, J. C., Lybaert, N., Steijvers, T., Depaire, B., \& Mercken, R. (2012). Family firm types based on the professionalization construct: Exploratory research. Family Business Review, 26(1), 81-99. doi:0894486512445614. 
Diamantopoulos, A., Riefler, P., \& Roth, K. P. (2008). Advancing formative measurement models. Journal of Business Research, 61(12), 12031218. doi:10.1016/j.jbusres.2008.01.009

Duller, C., Feldbauer-Durstmüller, B., \& Mitter, C. (2011). Corporate governance and management accounting in family firms: Does generation matter? International Journal of Business Research, 11(1), 29-46.

Flores, J. E., Jr., \& Grisci, C. L. I. (2012). Dilemas de pais e filhos no processo sucessório de empresas familiares. RAUSP-Revista de Administração, 47(2), 325-337. doi:10.5700/rausp1042

Frezatti, F., Relvas, T. R. S., Nascimento, A. R., Junqueira, E. R., \& Bido, D. S. (2010). Perfil de planejamento e ciclo de vida organizacional nas empresas brasileiras. RAUSP-Revista de Admistração, 45(4), 383-399. doi:10.1016/Soo80-2107(16)30469-1

Garcia-Castro, R., \& Casasola, M. J. (2011). A set-theoretic analysis of the components of family involvement in publicly listed and major unlisted firms. Journal of Family Business Strategy, 2(1), 15-25. doi:10.1016/j.jfbs.2011.01.002

Gersick, K. E., Davis, J. A., Hampton, M. M., \& Lansberg, I. (1997). De geração para geração: Ciclos de vida das empresa familiares ( $4^{\mathrm{a}} \mathrm{ed}$.). Rio de Janeiro, RJ: Negócio.

Giovannoni, E., Maraghini, M. P., \& Riccaboni, A. (2011). Transmitting knowledge across generations: The role of management accounting practices. Family Business Review, 24(2), 126-150. doi:10.1177/0894486511406722.

Gómez-Mejía, L. R., Cruz, C., Berrone, P., \& Castro, J. De. (2011). The bind that ties: Socioemotional wealth preservation in family firms. The Academy of Management Annals, 5(1), 653-707. doi:10.1080/19416 520.2011 .593320

Gómez-Mejía, L. R., Haynes, K. T., Núñez-Nickel, M., Jacobson, K. J., \& Moyano-Fuentes, J. (2007). Socioemotional wealth and business risks in family-controlled firms: Evidence from Spanish olive oil mills. Administrative Science Quarterly, 52(1), 106-137. doi:10.2189/ asqu.52.1.106

Gordon, L. A., \& Miller, D. (1976). A contingency framework for the design of accounting information systems. Accounting, Organizations and Society, 1(1), 59-69. doi:10.1016/0361-3682(76)90007-6

Granlund, M., \& Taipaleenmäki, J. (2005). Management control and controllership in new economy firms-a life cycle perspective. Management Accounting Research, 16(1), 21-57. doi:10.1016/j. mar.2004.09.003

Greiner, L. (1972). Evolution and revolution as organizations grow. Harvard Business Review, 5o(4). Recuperado de https://hbr.org/

Greiner, L. E. (1997). Evolution and revolution as organizations grow: A company's past has clues for management that are critical to future success. Family Business Review, 10(4), 397-409. doi:10.1111/j.17416248.1997.00397.x

Grzybovski, D., \& Vieira, L. (2012). Ciclo de vida das empresas familiares brasileiras de pequeno porte: Uma análise das características e dinâmica estrutural em uma rede de revenda de gás liquefeito de petróleo. TPA-Teoria e Prática em Administração, 2(2), 78-96.

Hair, J. F., Jr., Hult, G. T. M., Ringle, C. M., \& Sarstedt, M. (2014). A primer on partial least squares structural equation modeling (PLS-SEM). Thousand Oaks, USA: Sage Publications, Inc.

Hanks, S. H. (1990). The organization life cycle: Integrating content and process. Journal of Small Business Strategy, 1(1), 1-12.
Haustein, E., Luther, R., \& Schuster, P. (2014). Management control systems in innovation companies: A literature based framework. Journal of Management Accounting Control, 24(4), 343-382. doi:10.1007/so0187-014-0187-5

Hiebl, M. R., Duller, C., Feldbauer-Durstmüller, B., \& Ulrich, P. (2015). Family influence and management accounting usage-findings from Germany and Austria. Schmalenbach Business Review, 67(3), 368404 .

Holt, D. T., Rutherford, M. W., \& Kuratko, D. F. (2010). Advancing the field of family business research: Further testing the measurement properties of the F-PEC. Family Business Review, 23(1), 76-88. doi:10.1177/0894486509349943

Klein, S. B., Astrachan, J. H., \& Smyrnios, K. X. (2005). The F-PEC Scale of family influence: Construction, validation and further implication for theory. Entrepreneurship Theory and Practice, 29(3), 321-339. doi:10.1111/j.1540-6520.2005.00086.x

Lescura, C., Brito, M. J. D., Cappelle, M. C. A., \& Borges, A. F. (2012). A dinâmica Família-Empresa: Uma aplicação do método historiográfico e da técnica do genograma. Organizações \& Sociedade, 19(60), 67 86. doi:10.1590/S1984-92302012000100005

Lester, D. L., \& Parnell, J. A. (2008). Firm size and environmental scanning pursuits across organizational life cycle stages. Journal of Small Business and Enterprise Development, 15(3), 540-554. doi:10.1108/14626000810892337.

Lester, D. L., Parnell, J. A., Carraher, S., \& Pamell, J. A. (2003). Organizational life cycle: A five-stage empirical scale. International Journal of Organizational Analysis, 11(4), 339-354. doi:10.1108/ ebo28979.

Lester, D. L., Parnell, J. A., \& Menefee, M. L. (2009). Organizational life cycle and innovation among entrepreneurial enterprises. Journal of Small Business Strategy, 19(2), 37-50.

Lethbridge, E. (1997). Tendências da empresa familiar no mundo. Revista do BNDES, 7(1), 1-18.

Macêdo, K. B. (2002). Cultura, poder e decisão na organização familiar brasileira. RAE-Eletrônica, 1(1). Recuperado de http://rae.fgv.br/raeeletronica

Meireles, B. O., Debastiani, S. M., \& Rojo, C. A. (2015). Proposta de intervenção empresarial com base no ciclo de vida organizacional proposto por Greiner: 0 caso da Scherer Indústria de Implementos Agrícolas. Revista Capital Científico-Eletrônica (RCCe), 13(3), 111-123. doi:10.5935/2177-4153.20150025

Miles, R. E., \& Snow, C. C. (1978). Organizational strategy: Structure, and process. New York, USA: McGraw-Hill.

Miller, D. (1984). Organizations: A quantum view. Englewood Cliffs, USA: Prentice Hall.

Miller, D., \& Breton-Miller, I. Le. (2006). Family governance and firm performance: Agency, stewardship, and capabilities. Family Business Review, 19(1), 73-87. doi:10.1111/j.1741-6248.2006.00063.x

Miller, D., \& Breton-Miller, I. Le. (2014). Deconstructing socioemotional wealth. Entrepreneurship Theory and Practice, 38(4), 713-720. doi:10.1111/etap.12111

Miller, D., Breton-Miller, I. Le, Lester, R. H., \& Cannella, A. (2007). Are family firms really superior performers? Journal of Corporate Finance, 13(5), 829-858. doi:10.1016/j.jcorpfin.2007.03.004 
Miller, D., \& Friesen, P. H. (1983). Successful and unsuccessful phases of the corporate life cycle. Organization Studies, 4(4), 339-356. doi:10.1177/017084068300400403

Miller, D., \& Friesen, P. H. (1984). A longitudinal study of the corporate life cycle. Management Science, 30(10), 1161-1183. doi:10.1287/ mnsc.30.10.1161

Miller, D., \& Friesen, P. H. (1986). Porter's (1980) generic strategies and performance: An empirical examination with American data - Part I: Testing Porter. Organization Studies, 7(1), 37-55. doi:10.1177/017084068600700103

Moores, K., \& Yuen, S. (2001). Management accounting system and organizational configuration: A life cycle perspective. Accounting Organization and Society, 26(4-5), 351-389. doi:10.1016/S03613682(00)00040-4

Morais, É. D., \& Silva, W. A. C. (2014). Organizational life cycle and longevity: Analysis of the metropolitan industries Belo Horizonte/ MG from the approach of Greiner. Tourism \& Management Studies, 10(Special issue), 69-78.

Muzzio, H. (2012). Racionalidades em jogo em um processo de profis sionalização organizacional. RAC-Revista de Administração Contemporânea, 16(6), 827-844. doi:10.1590/S1415-65552012000600005.

Nordqvist, M., Sharma, P., \& Chirico, F. (2014). Family firm heterogeneity and governance: A configuration approach. Journal of Small Business Management, 52(2), 192-209. doi:10.1111/jsbm.12096

Oliveira, J. L., Albuquerque, A. L., \& Pereira, R. D. (2012). Governança, sucessão e profissionalização em uma empresa familiar: (Re) Arranjando o lugar de família multigeracional. Revista Brasileira de Gestão de Negócios, 14(43), 176-192.

Oliveira, L. G. M., \& Silva, G. A. V. da. (2012). Sucessão em uma empresa familiar: Valores, racionalidades e dilemas. Revista de Administração FACES Journal, 11(2), 28-42. doi:10.21714/19846975faces2012v11n2art1214

Oro, I. M., Beuren, I. M., \& Hein, N. (2009a). Análise da relação entre a estrutura de capital e o lucro operacional nas diversas gerações de empresas familiares brasileiras. Revista Contabilidade Vista \& Revista, 20(1), 67-94.

Oro, I. M., Beuren, I. M., \& Hein, N. (2009b). Análise da eficiência de empresas familiares brasileiras. RAE-Eletrônica, 8(2). Recuperado de http://rae.fgv.br/rae-eletronica

Paiva, K. C. M. de, Oliveira, M. C. de S. M. de, \& Melo, M. C. de O. L. (2008). Produção científica brasileira sobre empresa familiar - um metaestudo de artigos publicados em anais de eventos da ANPAD no período de 1997-2007. RAM-Revista de Administração Mackenzie, 9(6), 148-173. doi:10.1590/S1678-69712008000600008

Peiser, R. B., \& Wooten, L. M. (1983). Life-cycle changes in small family businesses. Business Horizons, 26(3), 58-65. doi:10.1016/00076813(83)90031-9

Pereira, A. C. S., Vieira, A., Garcia, F. C., \& Roscoe, M. T. de A. (2013). Desconstrução do mito e sucessão do fundador em empresas familiares. RAC-Revista de Administração Contemporânea, 17(5), 518535. doi:10.1590/S1415-65552013000500002

Petry, L. I., \& Nascimento, A. M. (2009). Um estudo sobre o modelo de gestão e o processo sucessório em empresas familiares. Revista Contabilidade \& Finanças, 20(49), 109-125. doi:10.1590/S151970772009000100008
Price Waterhouse-Coopers. (2010). As empresas familiares no Brasil. Recuperado de http://www.pwc.com/br

Quinn, R. E., \& Cameron, K. (1983). Organizational life cycles and shifting criteria of effectiveness: Some preliminary evidence. Management Science, 29(1), 33-51. doi:10.1287/mnsc.29.1.33

Ringle, C. M., Wende, S., \& Becker, J.-M. (2015). SmartPLS 3. Boenningstedt: SmartPLS GmbH. Retrieved from http://www. smartpls.com

Rodrigues, A. M. (1991). Padrões afetivos na família e empresa familiar. RAE-Revista de Administração de Empresas, 31(4), 35-48.

Schulze, W. S., \& Kellermanns, F. W. (2015). Reifying socioemotional wealth. Entrepreneurship Theory and Practice, 39(3), 447-459. doi:10.1111/etap.12159

Schulze, W. S., Lubatkin, M. H., \& Dino, R. N. (2003). Toward a theory of agency and altruism in family firms. Journal of Business Venturing, 18(4), 473-490. doi:10.1016/So883-9026(03)00054-5

Serviço Brasileiro de Apoio às Micro e Pequenas Empresas. (2013). Anuário do trabalho na micro e pequena empresa 2013. Recuperado de http://www.sebrae.com.br/Sebrae/Portal\%20Sebrae/Anexos/Anuario\%20do\%20Trabalho\%20 Na\%20Micro\%20e\%20Pequena\%20 Empresa_2013.pdf

Sharma, P. (2004). An overview of the field of family business studies: Current status and directions for the future. Family Business Review, 17(1), 1-36. doi:10.1111/j.1741-6248.2004.00001.x

Silva, A., Junior, \& Muniz, R. M. (2006). Sucessão, poder e confiança: Um estudo de caso em uma empresa familiar capixaba. RAUSP. Revista de Administração, 41(1), 107-117.

Silva, A., Junior, Silva, P. D. O. M. da, \& Silva, A. R. L. da (2013). Sistemas de valores e implicações na governança corporativa em um grupo empresarial familiar. Organizações \& Sociedade, 20(65), 239-260. doi:10.1590/S1984-92302013000200004

Sirmon, D. G., \& Hitt, M. A. (2003). Managing resources: Linking unique resources, management, and wealth creation in family firms. Entrepreneurship Theory and Practice, 27(4), 339-358. doi:10.1111/1540-8520.to1-1-00013

Speckbacher, G., \& Wentges, P. (2012). The impact of family control on the use of performance measures in strategic target setting and incentive compensation: A research note. Management Accounting Research, 23(1), 34-46. doi:10.1016/j.mar.2011.06.002

Sponem, S., \& Lambert, C. (2016). Exploring differences in budget characteristics, roles and satisfaction: A configurational approach. Management Accounting Research, 30, 47-61. doi:10.1016/j. mar.2015.11.003

Terence, A. C. F. (2002). Planejamento estratégico como ferramenta de competitividade na pequena empresa (Dissertação de mestrado, Universidade de São Paulo).

Tillmann, C., \& Grzybovski, D. (2005). Sucessão de dirigentes na empresa familiar: Estratégias observadas na família empresária. Organizações \& Sociedade, 12(32), 45-61.

Três, D. L., Serra, F. R., Pinto, R., \& Pereira, M. F. (2014). Ciclo de vida organizacional: Um estudo de caso em uma empresa familiar. Revista Ciências Administrativas, 20(2), 528-557. doi:10.5020/23180722.2014.v2on2p528 
Ven, A. H. Van de. (1992). Suggestions for studying strategy process: A research note. Strategic Management Journal, 13(S1), 169-188. doi:10.1002/smj.4250131013

Waiandt, C., \& Davel, E. (2008). Organizações, representações e sincretismo: A experiência de uma empresa familiar que enfrenta mudanças e sucessões de gestão. Revista de Administração Contemporânea, 12(2), 369-394. doi:10.1590/S1415-65552008000200005

Westhead, P., \& Cowling, M. (1998). Family firm research: The need for a methodological rethink. Entrepreneurship: Theory and Practice, 23(1), 31-33.
Westhead, P., \& Howorth, C. (2007). Types of private family firms: An exploratory conceptual and empirical analysis. Entrepreneurship \& Regional Development, 19(5), 405-431. doi:10.1080/08985620701552405.

Zahra, S. A., Neubaum, D. O., \& Larrañeta, B. (2007). Knowledge sharing and technological capabilities: The moderating role of family involvement. Journal of Business Research, 60(10), 1070-1079. doi:10.1016/j. jbusres.2006.12.01.

Zellweger, T. M., Nason, R. S., \& Nordqvist, M. (2011). From longevity of firms to transgenerational entrepreneurship of families: Introducing family entrepreneurial orientation. Family Business Review, 25(2), 136-155. doi:10.1177/0894486511423531. 